\title{
Cine, interdisciplinariedad y educación en valores: una experiencia en Kosovo
}

\section{Film, interdisciplinary and values education: An Experience in Kosovo}

\author{
Eduardo Negrín Torres (Universidad de Barcelona) \\ http://dx.doi.org/10.12795/AdMIRA.2010.01.09 \\ “... para nosotros lo realmente importante no es la meta que se \\ desea alcanzar, sino el camino que hay que recorrer”
}

Abbas Kiarostami ${ }^{1}$

\section{Resumen}

En el presente artículo proponemos el cine como herramienta de aprendizaje interdisciplinar. Consideramos que su potencialidad como medio artístico, visual y emocional aporta a cada integrante del equipo de trabajo un rol activo y estimula su autoestima, creatividad, reflexión y capacidad de trabajo cooperativo. Además, la experiencia referida se llevó a cabo en Kosovo, en un contexto de difícil convivencia entre distintas etnias que -en un pasado reciente- se vieron envueltas en una guerra. La construcción de una película por parte de un conjunto de niños supone un punto de encuentro integrador que se expresa, en último término, en un recuerdo permanente. Una película ideada y realizada por todos, que se puede volver a ver tantas veces como se quiera y que permite extender las reflexiones proyectadas sobre uno mismo y el entorno.

\begin{abstract}
In this paper we propose the cinema as a tool for interdisciplinary learning. We believe that its potential as an artistic, visual and emotional medium brings to every work team member an active role and encourages their self-esteem, creativity, reflection and cooperative working capacity. Moreover, the experience referred to took place in Kosovo, in a context of difficult cohabitation between different ethnic groups which -in the recent past- were involved in a war. The construction of a film by a group of children poses a integrative meeting which ultimately expresses itself as a permanent reminder. A film conceived and performed by all, which you can view as many times as you like and which can extend the reflections cast upon oneself and the environment.
\end{abstract}

Palabras clave: cine, educación, trabajo cooperativo, Kosovo.

Keywords: cinema, education, cooperative work, Kosovo.

\footnotetext{
${ }^{1}$ Abbas Kiarostami es un cineasta iraní nacido en 1940.
} 


\section{Introducción}

Los planteamientos de los curriculums educativos en nuestra época se enfrentan al importante reto de rellenar una brecha creciente que los separa de la realidad. La evolución constante de las formas de comunicación inter e intrapersonales en el entorno de la iconosfera potencian las posibilidades de adquisición de conocimientos, reflexión y trabajo cooperativo. Tanto es así que las nuevas generaciones se valen de Internet de un modo absolutamente espontáneo para relacionarse con los demás, aprender modas, entretenerse y para casi todo lo que se pueda llegar a pensar.

Este universo de la iconosfera se caracteriza, como su propio nombre indica, por presentar la imagen como medio expresivo primordial. Y como todo medio comunicativo, la imagen conlleva un lenguaje propio. Creemos que el lenguaje de la imagen -audiovisual en general- no tiene suficiente presencia como materia de aprendizaje en los programas educativos actuales.

Partimos de la base que el modelo educativo ha de integrar de manera didáctica la enseñanza del lenguaje audiovisual como herramienta de comunicación informativa, estética, didáctica y artística.

(...) Todo esto el artista lo reproduce en la creación de una imagen que de forma independiente recoge lo absoluto. Con la ayuda de esta imagen se fija la vivencia de lo interminable y se expresa por medio de la limitación: lo espiritual, por lo material; lo infinito por lo finito. ${ }^{2}$

¿Cómo ignorar el poder de la imagen en un contexto social y educativo dominado por ella? Este contacto diario que vive la sociedad del mundo occidental desarrollado con la imagen multiplicada supone un hito de gran importancia, que exige nuevas formulaciones sociológicas. "La cultura audiovisual o iconosfera genera un nuevo tipo de persona, modificada profundamente en cuanto a hábitos perceptivos, en cuanto procesos mentales y en cuanto a gustos” (Ferrés, 1994: 8).

Por ello, en esta jungla de la imagen bautizada como "la cultura mosaico" por Abraham Moles (1978), es preciso reflexionar acerca del lenguaje audiovisual y la importancia que entraña su aprendizaje en el ámbito escolar al mismo nivel de prioridad que el alfabético. En primer lugar, cabe destacar que el pulso entre la escuela y la

\footnotetext{
${ }^{2}$ Tarkovski, Andrei (1991). Esculpir en el tiempo. Madrid: Ediciones Rialp.
} 
enseñanza audiovisual nos llega desde el siglo pasado y, en consecuencia, existen valiosísimos estudios sobre su descripción y definición de sus causas. ${ }^{3}$

En suma, la perpetuación del desencuentro escuela/audiovisual ha llevado a varios autores a acuñar el término de "analfabetismo audiovisual” para definir la situación a la que se enfrentan tanto profesores como alumnos que no trabajan en el aula contenidos relacionados con el lenguaje de la imagen.

Y aún es más: se han abordado estudios científicos que exploran la importancia del lenguaje audiovisual para la naturaleza orgánica del hombre. Por ejemplo, el que demuestra que el tipo de estímulos perceptivos que recibe una persona afecta al grado de desarrollo de sus hemisferios cerebrales. Tal y como señala Joan Ferrés, los procesos mentales relacionados con la lectura y la escritura (de carácter analítico) pertenecen al dominio del hemisferio izquierdo, mientras que la descodificación de una imagen (ligada a la intuición) es tarea del derecho. Esta demostración científica lleva a valorar de forma concreta la metamorfosis perceptiva que supone un cambio significativo en los hábitos humanos de lectura, sobre todo en las nuevas generaciones: "Hoy el alumno es más capaz de comprender sintiendo o intuyendo que razonando o analizando” (Ferrés, 1994: 20).

Bajo esta perspectiva, creo que es necesario considerar el lenguaje audiovisual como una materia de estudio de primer orden. Y no sólo porque, como hemos dicho, se ha convertido en la "forma comunicativa hegemónica", sino también por su potencialidad como mecanismo de aprendizaje interdisciplinar en sí mismo.

Se trata de una responsabilidad social fortalecer la comprensión del lenguaje audiovisual para conducir a un mejor entendimiento a escala global. Prácticamente desde sus inicios, se ha criticado la influencia de los mass media sobre la cultura y sus valores, tildándolos de superficiales, especulativos, deformadores, etc. No obstante, aquí entendemos los medios audiovisuales como prolongaciones de las herramientas

\footnotetext{
${ }^{3}$ Michel Tardy escribe en su libro El profesor y las imágenes, publicado en el año 1978: "Diríase que los medios de comunicación de masas: cine y televisión, desafían a la pedagogía y son una constante invitación a discutirla a examinarla con una crítica radical. Los pedagogos, con admirable y obstinada constancia, hace tanto tiempo que han condenado o vuelto la espalda por evidente orden al cine y a la televisión, que han precipitado el momento de la represalia”.
} 
comunicativas humanas y por tanto, su naturaleza y finalidad dependen del modo en que se expriman. En palabras de Marshal McLuhan:

Si los medios de comunicación masiva nos sirvieran sólo para debilitar o corromper niveles anteriormente alcanzados por la cultura verbal y de la imagen, no sería porque hay en ellos algo inherentemente malo, sería porque no hemos podido dominarlos con nuevos lenguajes para integrarlos en la herencia cultural global $^{4}$.

Es por esta razón por la que el cine (tanto mirado como hecho) tiene una trascendencia extraordinaria: supone un pasadizo mágico para revelar realidades distintas a la propia, enfrentarse a sentimientos propios y ajenos y reflexionar sobre lo que acontece en el entorno.

\section{El cine como herramienta de aprendizaje interdisciplinar}

Esta necesidad persigue crear un joven espectador activo y crítico que en lugar de ver el cine y la televisión sin poder descifrar contenidos y mensajes interesados y no inocentes, sea capaz de formar una mirada propia en constante búsqueda y alerta, una mirada despierta.

Como hemos dicho anteriormente, desde hace algún tiempo se viene hablando sobre la necesidad de desarrollar el currículo integrado en las aulas.

A modo de reflejo de la sociedad "fordista", 5 la educación de mediados de siglo tendió a la excesiva fragmentación de las materias de estudio y a la separación radical de las distintas disciplinas con el fin de formar profesionales muy especializados en cada campo. Sin embargo, fueron muchas las voces de educadores y estudiosos que revelaron los peligros de la escisión instrumental de saberes. Entre los riesgos más representativos destacamos la desorientación social causada por la concentración en una parcela concreta del conocimiento (cada trabajador / alumno se limita a su campo de estudio /

\footnotetext{
${ }^{4}$ Marshall McLuhan, educador y filósofo canadiense, indagó en la naturaleza y relevancia de los medios de comunicación. Entre otros conceptos, desarrolló el que concibe a las herramientas mediáticas como prolongaciones del hombre.

5 "Sociedad fordista" (en alusión Henry Ford, fundador de la multinacional automovilística) es un término acuñado por los sociólogos en referencia a las formas de producción propias del apogeo de la revolución industrial; esto es, cadenas de montaje, serialización del trabajo y fragmentación de la escala productiva, en la que el trabajador se especializa en una tarea repetitiva y desconoce las características globales de su labor concreta.
} 
trabajo y desconoce las demás realidades, situaciones y áreas de conocimiento) ${ }^{6}$. Y también el distanciamiento e incomunicación que provoca la falta de comprensión integral de la realidad entre campos de conocimiento, trabajadores y sociedades. Todo ello en favor de un conocimiento utilitario en términos de producción económica y rentabilidad laboral y en detrimento del diálogo y la empatía integral.

Estos dos ejemplos revelan que los esfuerzos realizados por unidades especializadas aisladas pueden llegar a ser contraproducentes para esas mismas unidades y terriblemente desestabilizadores en la dimensión colectiva.

En el terreno educativo, la aplicación de currículums interdisciplinares permiten demostrar que los fenómenos no existen por separado, facilitan una visión más integral de la unidad y la diversidad del mundo natural y social, así como su implicación ética en la sociedad. La interdisciplinariedad no niega a las demás disciplinas, sino que establece una relación dialéctica entre ellas. Análogamente, un aprendizaje integrado da lugar a personas que dialogan entre ellas porque conocen las realidades ajenas y la propia como parte de un conjunto complejo, habiendo superado la obsesión parcelada a la que antes hacíamos referencia. Además, no solo encontramos fundamentos de carácter socioeconómicos en este aspecto, sino que también existen razones particulares:

La interdisciplinariedad tropieza con los intereses gremiales de los especialistas, las ambiciones territoriales de los académicos y el desinterés para todo lo que no sea el corto plazo de los administradores públicos. Son dificultades extrínsecas a las que hay que sumar las intrínsecas o propias: Babelización de la cultura, multiplicación de lenguajes especializados, proliferación de metodologías ultraespecíficas, etc. ${ }^{7}$.

Es aquí donde propongo el cine como una herramienta híbrida por naturaleza que cumple los requisitos para ser un medio de aprendizaje interdisciplinar. Y, al final del presente trabajo, explicaré una experiencia propia que confirma el grado y el valor potencial del medio según el uso que de él se haga.

En palabras de Saturnino De la Torre:

\footnotetext{
${ }^{6}$ Jurjo Torres describe minuciosamente en su libro Globalización e interdisciplinariedad: El currículum integrado las reacciones disidentes a la educación fordista y las propuestas alternativas que surgieron durante la época.

${ }^{7}$ Arana, Juan (2001). ¿Es posible la interdisciplinariedad? Teoría y práctica. http://www.unav.es/gep/PosibleInterdiscip.html
} 
El relato fílmico tiene un efecto de desarrollo cerebral, cognitivo-emotivo, superior a otros sistemas de información si lo utilizamos como estrategia didáctica interactiva. El cine estimula todo el cerebro (ambos hemisferios) y una buena película que hace pensar, comporta valores y crea dilemas, tiene un potencial formativo superior a cualquier sistema tradicional, por lo que trasmite, por lo que sugiere y por lo que hace pensar y sentir. (De la Torre, 2005: 32).

La mezcla de las dos dimensiones del contacto con el exterior de una persona, el pensamiento y el sentimiento, lo intelectual y lo emocional, se da de manera total en una película cinematográfica. Durante el visionado de una película se produce una estimulación multisensorial en el espectador: la naturaleza psicológica y emocional de los personajes, el contexto narrativo, el flujo dramático, la simbología musical e icónica, la identificación y el rechazo de la realidad. Todos estos elementos provocan un "efecto espejo" que refleja un conjunto de preguntas, sentimientos, aprendizajes, pareceres que enriquecen un debate posterior.

En este punto, el espectador pone en juego sus conocimientos y valores intra e interpersonales. A través de una película, ya sea de ficción o documental, el espectador encuentra "otra" realidad en la que observarse y observar. Rechazando una idea de verdad absoluta, si que creemos que cada espectador conoce o reconoce en un film realidades próximas y lejanas, maneras de actuar, modelos referenciales de identidad, formas poéticas y simbólicas, concretas y determinadas. La muestra de matices singulares del mundo en su globalidad dentro de un lenguaje que se adapta a la evolución tecnológica sin perder un ápice de su fuerza expresiva, creativa y recreativa.

En sí mismo, el medio cinematográfico supone una apertura de la imaginación de quien lo observa y de quien lo hace, permite ponerse en el lugar del otro, viajar a otros lugares del mundo, verse en otras situaciones. Como decíamos al principio, la intervención educativa a través del cine enlaza transversalidad e interdisciplinariedad desde una perspectiva que genera interés en el alumnado y consigue aprendizajes selectivos, no memorizados, que perduran en el tiempo. Juicio crítico e investigación-acción, es decir, ver y hacer cine.

\section{Cine y educación en valores}


Los tres pilares fundamentales del aprendizaje en valores son el cognoscitivo, el afectivo y el comportamental ${ }^{8}$. Estos tres componentes explican las actitudes que toman las personas según los condicionamientos de su entorno. El elemento cognoscitivo conforma lo que la persona piensa o cree sobre algo, el afectivo representa lo que la persona siente y el comportamental, lo que la persona hace.

Por ello, desde el punto de vista de la educación en valores, la interdisciplinariedad a través del cine agudiza el componente cognoscitivo a través de la identificación de valores intrapersonales (autoconocimiento, identidad) e intrapersonales (cooperación, respeto, empatía). Ahonda en el valor afectivo, contribuyendo a la gestación de actitudes coherentes con los valores reflexionados. Y, por último, canaliza el valor comportamental, motivando en la persona conductas inspiradas en las actitudes pensadas y sentidas, de modo que responden al proceso de reflexión previo y suponen un aprendizaje significativo al surgir espontáneamente.

\section{Experiencia en Kosovo: Taller cinematográfico con niños de Kosovo.}

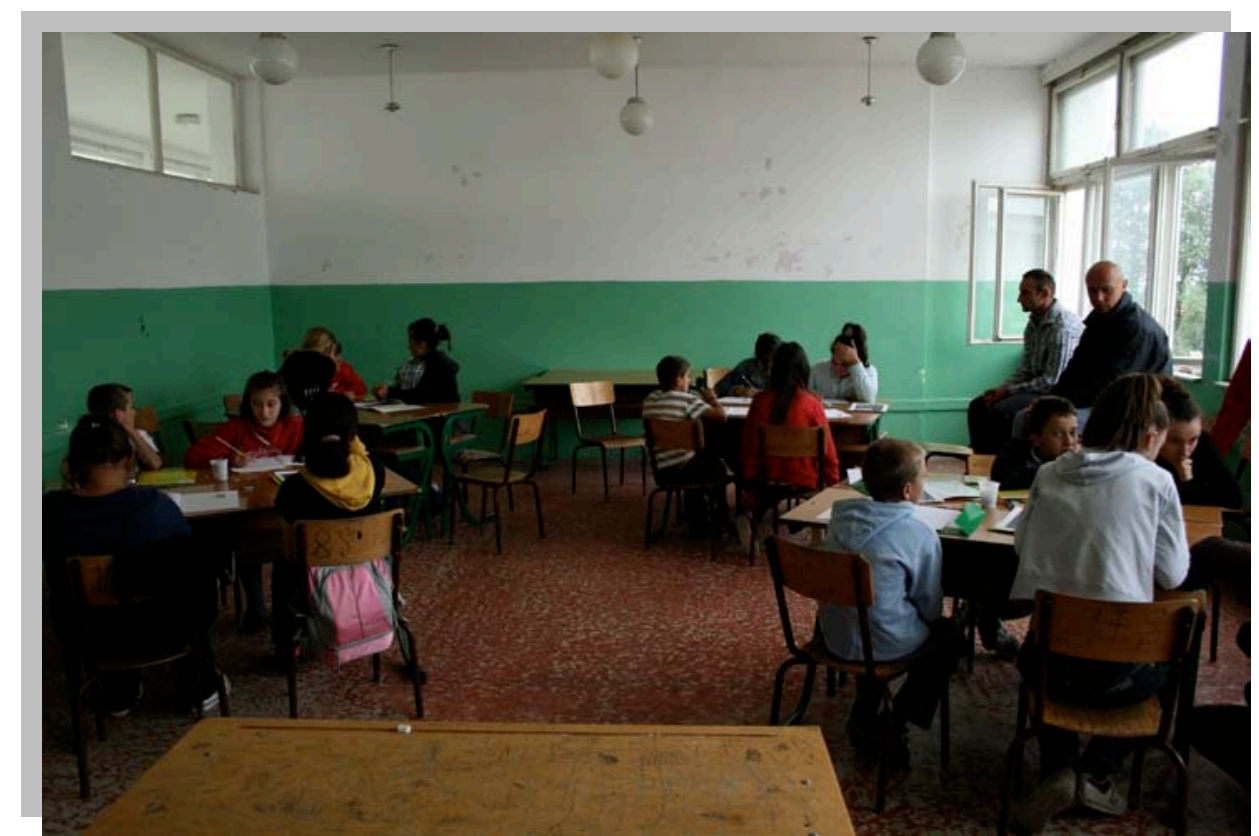

Imagen 1: Los participantes escriben el primer borrador de guión durante la primera fase del Taller.

Los participantes del taller, alumnos de tres etnias diferentes y residentes en el poblado de Banja (Kosovo), son herederos de un pasado reciente trágico. Durante los años 1996

\footnotetext{
${ }^{8}$ Según el modelo formulado por Azjen y Fishbein en el año 1980.
} 
y 1999, el ejército serbio y la población albanesa libraron una batalla sangrienta que terminó en tragedia para ambos bandos, como sucede en cualquier guerra. Los hijos de los combatientes de ambos bandos acuden a la única escuela de su pueblo junto con los de las otras dos etnias mayoritarias, bosnios y gitanos quienes, de diversas formas, también se vieron envueltos en la masacre. Los padres de los albaneses y los serbios se niegan a que ninguna institución u ONG trate de integrar a sus hijos en actividades conjuntas. Hasta el momento, no han acercado posturas en el terreno político y persisten algunos enfrentamientos aislados. Por lo tanto, el taller cinematográfico se realizó con niños albaneses, bosnios y gitanos cuyos mayores, aún manteniendo serias rencillas, sí aceptan que sus hijos se mezclen en un contexto de taller interdisciplinar promovido por ONGs (única fuente de recursos junto con la ayuda humanitaria que despliegan fuerzas de la OTAN en la región, dado el caos económico en el que vive sumido el país).

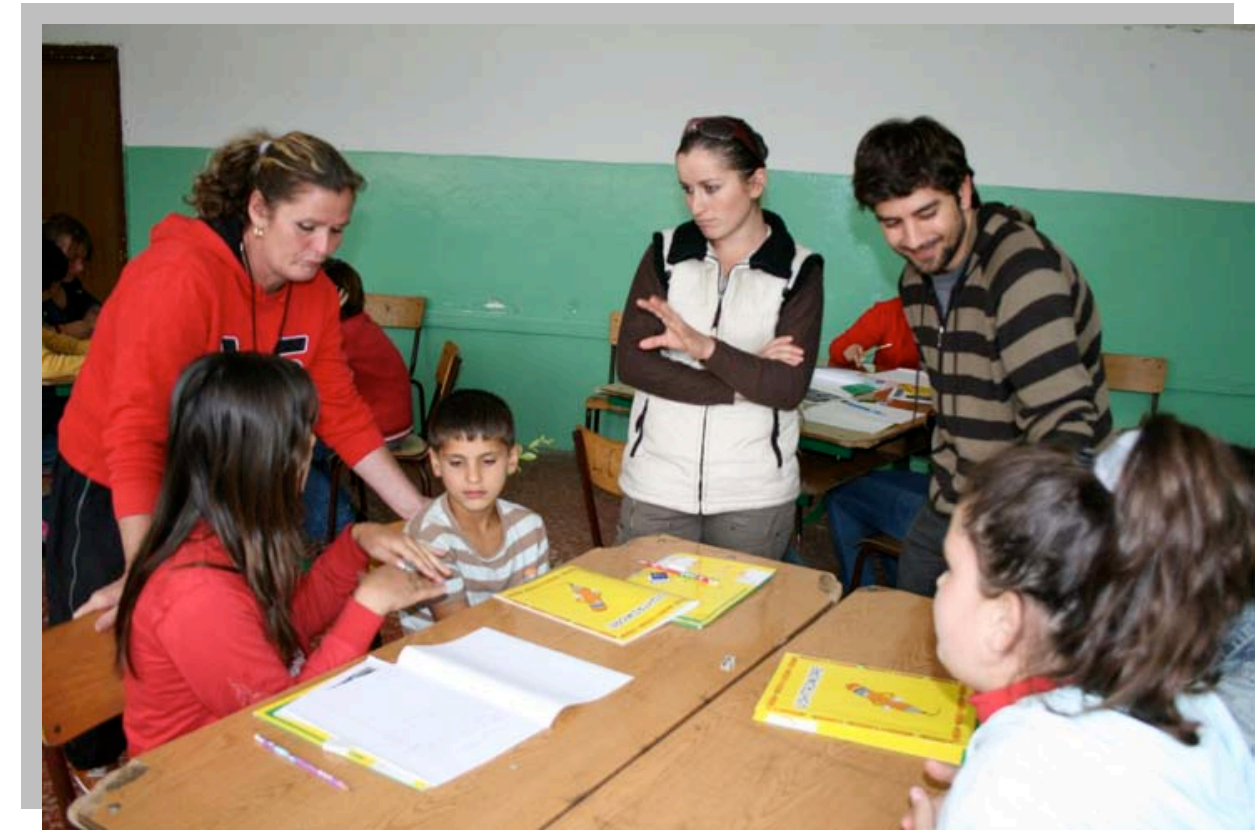

Imagen 2: La profesora de Educación Física del Instituto, la intérprete y yo respondemos las preguntas de los participantes.

\section{Descripción del taller}

El taller que dirigimos nació como propuesta independiente dentro del proyecto Formación en valores a través del deporte, desarrollado por la ONG Red Deporte y Cooperación y financiado por la Comunidad de Madrid. La idea inicial consistía en reunir a un grupo de 16 niños de las cuatro etnias mayoritarias de Kosovo en un aula de la escuela pública de Banja para construir juntos una película de ficción. Pronto recibimos la negativa por parte de los padres y profesores serbios del centro, situación 
que no nos extrañó porque ya nos habíamos encontrado con la misma respuesta para otras actividades que desarrollamos anteriormente.

Sin embargo, decidimos continuar con la propuesta y conseguimos el permiso de los padres de 16 alumnos para que participaran en el taller cinematográfico en horario extraescolar. Los niños tenían una edad comprendida entre los 8 y los 15 años y representaban a las etnias albanesa, bosnia y gitana. El taller se dividió en tres sesiones de tres horas cada una y en horario de tarde, con el fin de no interrumpir el horario de clases habitual de los participantes. Además, contamos con la colaboración imprescindible de Neta, intérprete albanesa, y de Djuke, profesora de Educación Física del instituto, que se ofreció voluntariamente como representante del centro y facilitó en todo momento la iniciativa al considerarla de gran interés para sus alumnos ${ }^{9}$.

Al carecer de intérprete de bosnio, decidimos aceptar el ofrecimiento de una alumna bilingüe de albanés y bosnio, que se erigió como interlocutora entre el grupo de bosnios y la intérprete albanesa. Por lo demás, la comunicación entre nosotros, de habla española, y los alumnos de habla albanesa y bosnia (los gitanos hablan mayoritariamente la lengua albanesa) resultó un juego divertido y, en ocasiones, surrealista. Cada comentario, sugerencia, duda o instrucción que hacíamos en español era traducida al albanés por la intérprete $\mathrm{y}$, a su vez, al bosnio por la alumna interlocutora. Y, finalmente, el proceso se repetía a la inversa para traer la contestación de los alumnos hasta nosotros. Se trataba de una escalera de filtrajes del mensaje que generaba nuevas interpretaciones hasta completarse en una "nueva forma". Una analogía curiosa con el trabajo que nos propusimos hacer: escribir un guión de cortometraje, planificar el lenguaje audiovisual para trasmitirlo, interpretarlo y filmarlo. La última fase del proceso, el montaje, no pudo realizarse in situ como nos hubiera gustado hacer para culminar el proceso de creación por carecer de infraestructura adecuada.

\footnotetext{
${ }^{9}$ La profesora de Educación Física del instituto de Banja era abiertamente partidaria a la mezcla de alumnos de distintas etnias en el aula como método de convivencia constructiva y superación de las heridas de la guerra. Su apoyo resultó muy fructífero al tratarse de una profesora que gozaba de gran confianza por parte de sus alumnos y cuya presencia aportó fluidez y concentración al taller.
} 
Como decíamos, la analogía reside en la convergencia de tantos puntos de vista como participantes en la aproximación a una realidad, a un tema del film. Por lo que la descodificación del contenido y de la forma se esculpen por el grupo, transformando los diferentes mensajes en un guión marcado por la singularidad de cada integrante. A continuación, la concentración conseguida en un guión escrito se vuelve a soltar, se vuelve a expandir en una forma de "nueva realidad” o "realidad otra" que se libera de la constricción textual para adquirir una naturaleza expandida como representación (divergencia). Así como un mensaje que se traduce a varias lenguas llega a su destinatario final conservando una esencia y modificando su forma, el cine en construcción grupal propone un mensaje compuesto por esencias de muchos mensajes que se concentran en un núcleo narrativo común. Y para ello, precisa de una reflexiónacción activa de todos los participantes, que intervienen en distintas fases del proceso de gestación de la idea y de su escritura. Es durante el período de debate natural entre las distintas propuestas que se van entreverando entre sí cuando los participantes contrastan sus creencias, valores, conocimientos y actitudes para, finalmente, tomar decisiones consensuadas por el grupo que consolidan la acción.

A diferencia del uso del cine como recurso pedagógico en su versión de visionado (cine-forum), un taller de cine en construcción permite reflexionar a priori sobre el “entorno” y el "uno mismo", para moldear la perspectiva o el tratamiento de un tema y de una realidad "realizada". No se trata, como en el cine-forum, de analizar o valorar una trama y una serie de realidades, valores y actitudes expuestas por otro film, sino de procesar, idear y mesurar la ficción antes de verla. Ponerse en el lugar de los personajes y los contextos que se imaginan, que se piensan y que se sienten, antes de hacerlos nacer en el guión y de “vivificarlos” en la acción. En el fondo, se trata de un ejercicio de aprender a mirar activamente.

Durante este taller, hemos comprobado la puesta en práctica de competencias tales como la cooperación, el saber escuchar, comunicación en voz alta y ordenada para la comprensión de los participantes, síntesis de ideas, reflexión de valores, comunicación no verbal, escritura creativa, compromiso con una idea común, etc. 


\section{Metodología de trabajo}

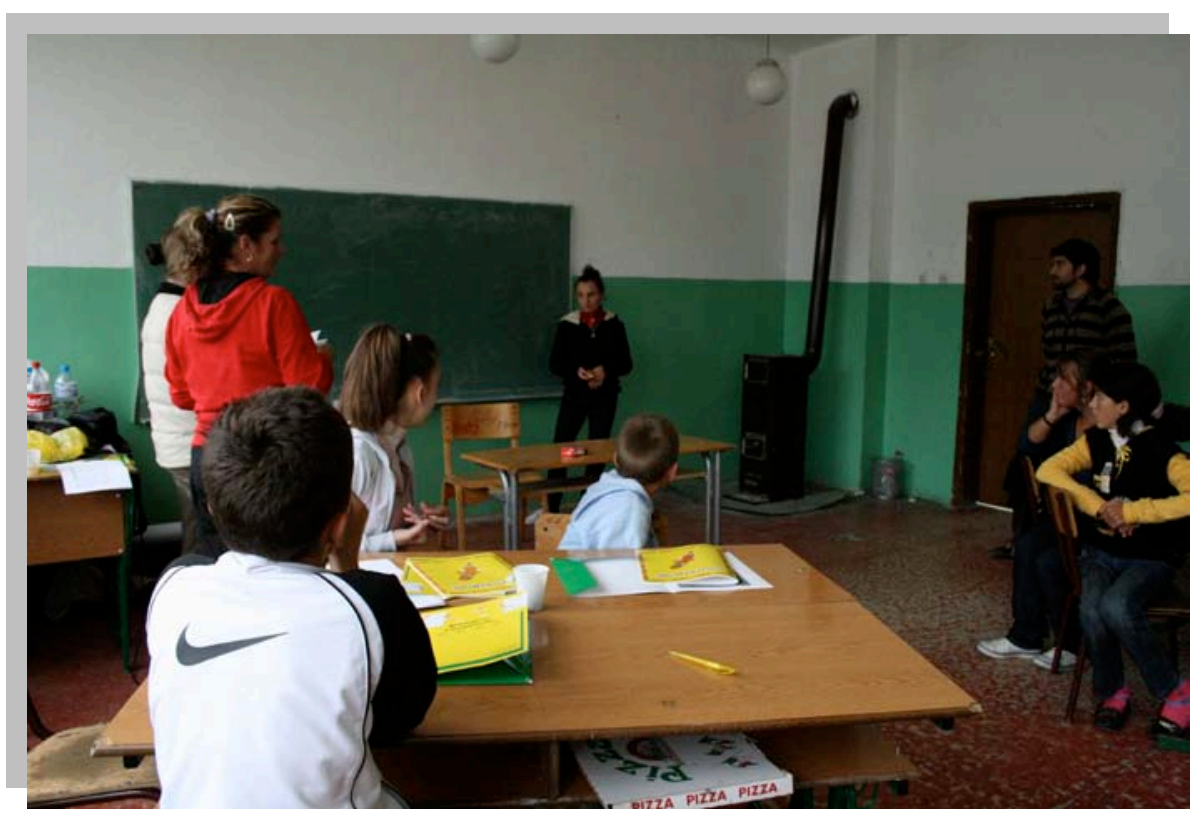

Imagen 3: La representante de uno de los grupos explica las líneas narrativas esenciales de su propuesta de guión ante la atenta mirada de sus compañeros.

\section{Fases estructurales del taller}

1. Breve presentación de la técnica y el lenguaje audiovisual. Este punto se realizó a través de un esquema básico que entregamos a los participantes y que comentamos entre todos: cómo se hace una película, qué elementos técnicos se necesitan para su filmación, dónde se coloca el equipo técnico y humano, cómo se graba el sonido, cómo se componen los planos y qué valor narrativo tienen, cómo se edita el material grabado, etc. Los participantes se interesaron mucho por el proceso de creación cinematográfico, una vez les fue traducido el texto por la intérprete. Muchos sacaron a colación las telenovelas latinoamericanas -muy populares en la región- y otras películas de acción de factura hollywoodiense. Muchos mostraron su sorpresa al reflexionar sobre aspectos importantes como que los planos se graban uno por uno, según la localización y las necesidades expresivas del contexto narrativo; los actores actúan para la cámara porque solo se registra una parte de la realidad delimitada por el marco, cada plano requiere una iluminación particular porque esto tiene una trascendencia dramática; debe existir una continuidad en lo que se graba y no siempre es posible filmar todas las secuencias en orden cronológico (de ahí la necesidad de un script ${ }^{10}$ que vele por la continuidad de la

\footnotetext{
${ }^{10}$ También llamado “continuista”, es una figura del equipo de rodaje cinematográfico encargada de verificar que la puesta de escena, el atrezo, vestuario, acción de los actores, posiciones y cambios del
} 
película), la sensación de realidad comprensible que ofrece un film se debe al principio de montaje cinematográfico que encadena planos entre sí mediante una ilusión de unidad espacio-temporal; y la variabilidad de estos elementos para conseguir resultados originales.

2. Elección de un tema consensuado por el grupo. A partir de las propuestas de los participantes, se abrió un debate entorno a la temática a escoger para comenzar a perfilar una idea como punto de partida para el guión literario. En el caso de nuestro taller, las ideas propuestas rondaban el tema de los derechos humanos, valores universales, etc. Tras escuchar unas y otras impresiones, el diálogo del grupo se fue centrando poco a poco en los derechos humanos como referencia: derecho a la escolarización de todos los niños, facilitar la convivencia entre las diversas etnias, respeto mutuo a las distintas identidades y esfuerzo compartido para mejorar la situación del pueblo, etc. Es normal la preocupación y sensibilidad por estos asuntos, dada la realidad que les ha tocado vivir, una herencia directa emanada de las heridas de una guerra reciente, sumada a la constante visita al instituto de distintas ONGs internacionales que, de uno u otro modo, difunden ideas relacionadas con estos temas. Finalmente, decidimos centrar esta premisa como punto de partida con el que empezar a elaborar un guión literario.

3. Elaboración del primer borrador grupal de un guión literario. Para ello, dispusimos a los 16 participantes en grupos de cuatro integrantes, que se formaron por libre asociación. Los cuatro grupos se sentaron en pupitres independientes para favorecer la concentración y el diálogo. Procuramos que los cuatro bosnios (que se agruparon voluntariamente) comprendieran las traducciones que de nuestras pautas hacía la intérprete albanesa y que, a su vez, volvía a traducir la alumna intérprete de bosnio a su grupo. Las respuestas que nos daba el grupo eran coherentes, con buen ritmo, así que no sentimos ningún tipo de descompensación con respecto al resto. En primer lugar, propusimos la elaboración de una sinopsis de una historia completa ${ }^{11}$. En

guión mantienen una lógica coherente entre planos. De forma que si dos o más planos de una misma secuencia se ruedan en dos momentos diferentes encajen entre sí sin que haya errores de continuidad. Además, se encarga de realizar anotaciones relativas a las tomas realizadas, posiciones de cámara y objetivos utilizados en cada momento.

11 Creímos conveniente comenzar con la propuesta de un relato general, para fomentar una visión panorámica de una realidad desde la cual empezar a encontrar coincidencias narrativas entre los 
unos minutos, los participantes comenzaron a debatir con agilidad y, poco después, aparecieron los primeros esquemas iniciales de narración. Para facilitar la comprensión de cada sinopsis grupal por parte de todos los presentes, pedimos un voluntarioportavoz de cada uno para que explicara en voz alta su propuesta. Además, pedimos que anotaran las líneas maestras del argumento en la pizarra para tener un registro simultáneo de las cuatro propuestas. Una vez comprendidas todas, abrimos un nuevo debate para encontrar puntos de coincidencia y de diferencia respecto a la realidad planteada, enfoque, tipo de personajes, acción y argumento. Todas las historias tenían por protagonista a un niño. Feliz coincidencia. A partir de ahí, la solidaridad y el afecto convivían de distintas maneras en todos los relatos con distintos signos de valor: padres que refugiaban a niños de otras etnias en sus casas, profesores que expulsaban a niños de sus aulas a causa de su identidad, exclusión de un grupo de niños por su nivel económico, etc. Y, en dos de ellos, el conflicto de la trama se solucionaba con la celebración de una fiesta multitudinaria.

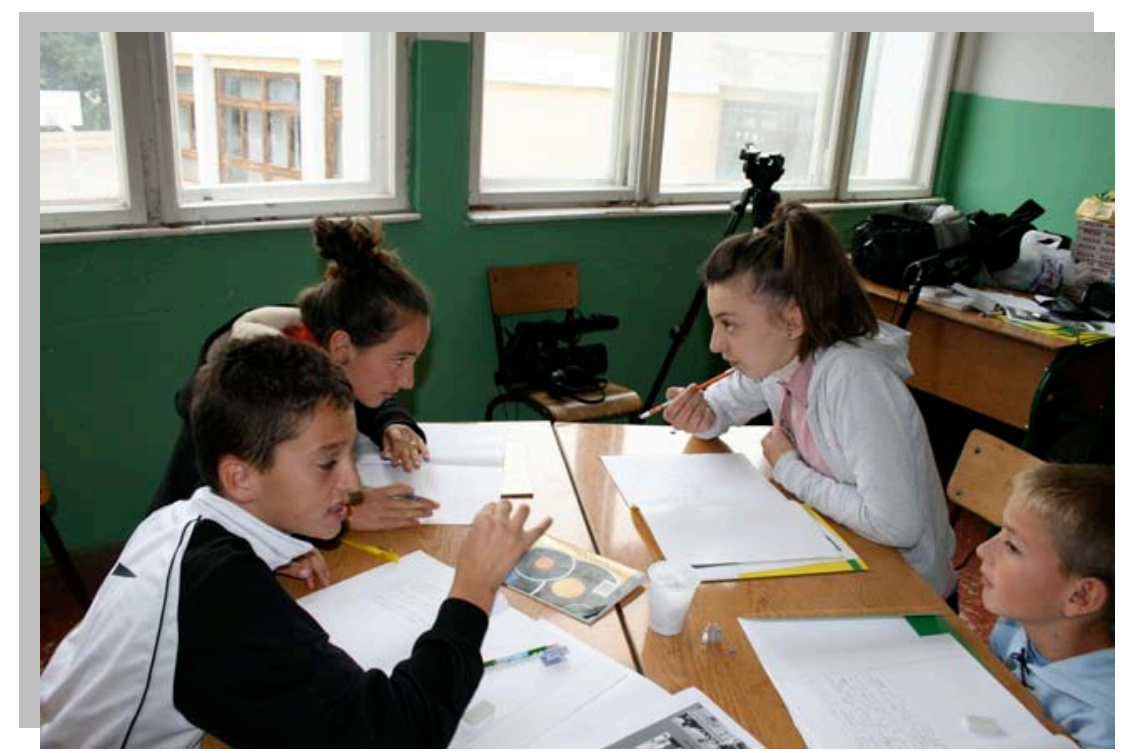

Imagen 4: Uno de los grupos, compuesto por alumnos de diferentes edades, se esfuerzan durante el proceso de escritura.

4. Conjunción de los cuatro borradores en un guión compartido. En el mismo proceso, los participantes escogieron las tramas más interesantes de cada propuesta atendiendo a las posibilidades combinatorias entre las cuatro sinopsis. De esta manera,

diferentes grupos, hasta el punto de encontrar una historia común. Todo ello, con el objetivo de que cada grupo acabara desarrollando en detalle una de las partes del guión definitivo. 
cada grupo seleccionaba los personajes, las acciones y las subtramas de sus ideas iniciales para que se entrelazaran coherentemente con las de los otros grupos. En los casos de bloqueo, en los que la decisión no quedaba clara o había que optar por una u otra propuesta, era la mayoría la que decidía ${ }^{12}$.

\section{La sinopsis del guión compartido quedó fijada de la siguiente forma:}

Un niño pobre y una niña bosnia sufren el rechazo de los alumnos del colegio. A pesar de que la solución parece irreversible, el niño confía en sus compañeras y trata de convencer a su única amiga de que sólo superando los prejuicios pueden alcanzar la amistad. Un cambio de actitud de todos los personajes permite que celebren una fiesta juntos.

Tras un debate intenso, con participación de todos los grupos (que supuso uno de los momentos de mayor dificultad para los intérpretes y los participantes a la hora de entendernos en el diálogo), se trazaron las líneas maestras del argumento.

\section{El argumento general cobró el siguiente camino:}

Un niño pobre sin escolarizar se acerca al patio del colegio y observa a varios alumnos jugando a la pelota. Cuando intenta sumarse a ellos recibe un rechazo unánime y, cabizbajo, regresa a su casa. Los alumnos que expulsaron al niño se sienten incapaces de seguir jugando y hablan entre ellos.

Al día siguiente, varios de ellos van a hablar con el director del colegio y le piden que acepte al niño pobre, asegurándole que han hablado con sus padres quienes están decididos a afrontar los gastos de su matrícula. El niño pobre asiste al colegio y aún no tiene amigos. Una pelota que cae cerca de él hace que se levante en su busca y, en ese momento, el grupo de alumnos que lo rechazó inicialmente le deja una bolsa con los libros de la escuela y algo de ropa en el lugar en el que estaba.

Al regresar de buscar la pelota, el niño pobre encuentra el regalo y ojea los libros con alegría. En su casa, el niño pobre cuenta a sus padres lo sucedido. Por otro lado, una niña inadaptada debido a su etnia (es bosnia en un colegio de albaneses)

\footnotetext{
${ }^{12}$ En este caso, se trata de una mayoría aproximada, es decir, no se hacía una votación numérica sino que la suma de voces favorables a una u otra propuesta en el instante de la toma de decisión daba la solución.
} 
conspira contra sus compañeras. Poco después, el niño pobre y la niña inadaptada se encuentran en un rincón solitario del colegio. Allí, la niña se desahoga e intenta poner al niño en contra de sus enemigas. El niño intenta convencerla de que debe hacer un esfuerzo para vencer sus prejuicios y reconciliarse con ellas. Sin embargo, en el patio del colegio, un nuevo desencuentro entre la niña y sus compañeras desemboca en una pelea.

Más tarde, las compañeras hablan entre sí y deciden organizar una fiesta sorpresa para la niña inadaptada y el niño pobre. Para asegurarse de que asisten, una de las chicas introduce una invitación con la hora y el sitio del encuentro en la libreta de la niña, sin que ésta se percate. Sin embargo, el niño pobre escucha la conversación de las compañeras que organizan la fiesta y está al tanto del plan, aunque decide no comunicárselo a su amiga, la niña inadaptada y sonríe feliz. Ambos acuden a la cita y se unen al baile grupal.

5. Desarrollo por grupos de las distintas partes del guión único. En esta fase del proyecto, que a nosotros nos parecía una de las más importantes, impulsamos a los participantes a hacer un esfuerzo de cooperación dialogada. Se trataba de construir entre todos una subtrama concreta y desarrollada para cada fase del guión. Escoger y definir a los personajes que hubieran de intervenir en el relato, redactar los diálogos que dieran coherencia a la narración ${ }^{13}$, pulir el signo de los puntos de giro del relato para crear una coherencia interna entre secuencias, escoger las localizaciones de cada secuencia y articular las conexiones entre los cuatro fragmentos. Para ello, dividimos nuevamente el trabajo bajo la premisa de asignar a cada grupo, en la medida de lo posible, las partes de guión nacidas de sus ideas originales ${ }^{14}$.

\footnotetext{
${ }^{13}$ Para la escritura de diálogos fue necesario hacer una breve explicación sobre la importancia de distribuir el carácter de un acontecimiento y la información que hubiera de darse para su comprensión a través de varios personajes. Para ello, planteamos el ejercicio de imaginar todas las caras de una acción, los puntos de vista subjetivos de los distintos integrantes de un conflicto narrativo. Definir las personalidades y la perspectiva de cada uno de ellos. Y, a partir de esta imagen mental, construir los diálogos de forma natural, sin incluir demasiada información en un solo personaje. También explicamos el formato en el que se deben escribir los diálogos en un guión para que sean comprensibles. Esto es, no en el interior del párrafo descriptivo, sino del modo: "Niño: ¿Puedo jugar a la pelota con ustedes?".

${ }^{14}$ En este caso, la asignación resultó aproximada, puesto que al unir las cuatro ideas originales en una sola, el resultado rebasó una parcelación exacta. Por lo tanto, procuramos dar a cada grupo la parte del guión que tuviera más elementos derivados de su idea original.
} 
Esta fase duró aproximadamente el doble del tiempo que se necesitó para elaborar la sinopsis. Los participantes se toparon con la dificultad de llegar a puntos de encuentro con los miembros de su grupo a la hora de elaborar diálogos concisos que trasmitieran la información necesaria. Por ello, comentamos la situación uno a uno, haciendo uso de ejemplos surgidos en otros grupos para la mejor comprensión del proceso.

Pasado este punto, nos sorprendimos de la agilidad con la que se construyeron diálogos complejos, incluso entre más de dos personajes a la vez. Para su elaboración, los grupos decidieron de manera espontánea que uno de sus miembros escribiera en el cuaderno, mientras el resto aportaba ideas, sometiéndolas a un breve debate antes de fijarlas.

Cuando los cuatro grupos hubieron terminado, los portavoces de cada uno de ellos leyeron en voz alta sus fragmentos. A continuación, se resolvieron de manera colectiva los puntos de intersección entre ambos, asunto que no revistió mayor dificultad dado que habíamos advertido la necesidad de pensar en posibles conexiones finales de su fragmento con el siguiente. Así que sólo supuso una nueva decisión por mayoría. Por ejemplo, el paso de la secuencia en que las niñas piden al director del colegio que admita al niño pobre en el centro a la siguiente, que comenzaba con el niño pobre ya admitido.

\section{Definición de atrezo, intérpretes, vestuario y localizaciones finales}

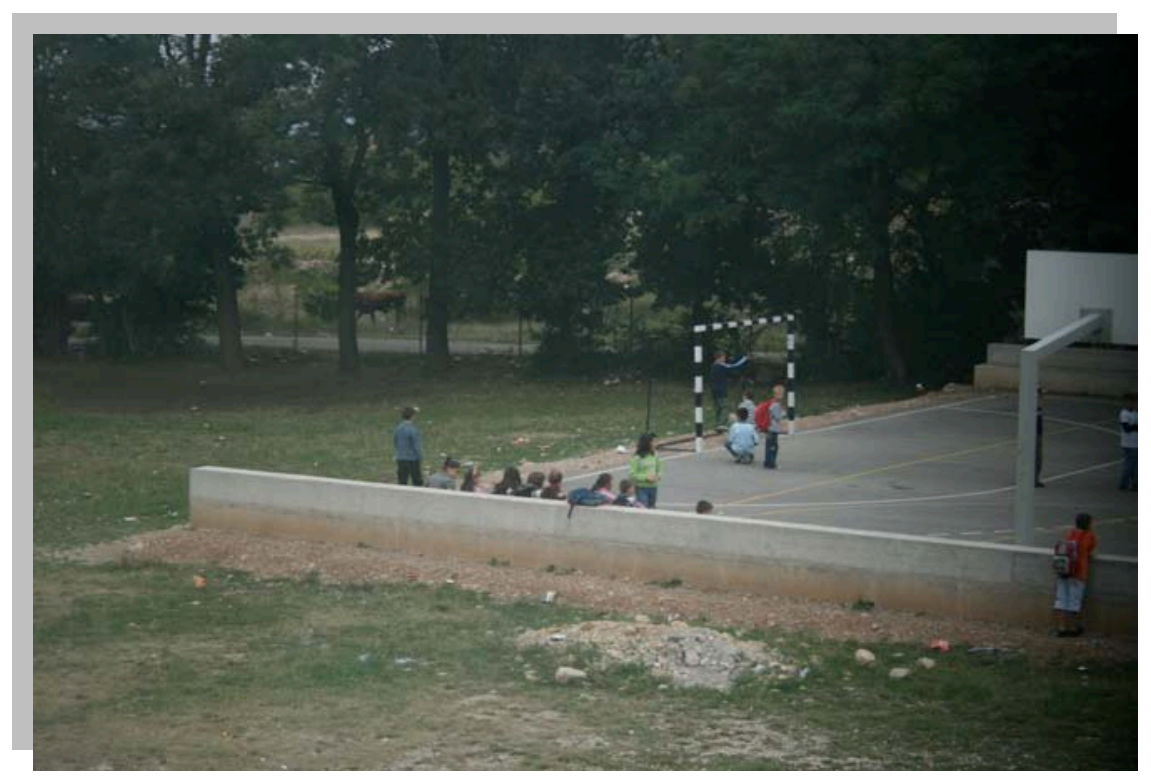

Imagen 5: Patio del colegio de Banja en el que se realizó el Taller, visto desde la ventana de un aula. 
No cabe duda de que en cualquier rodaje audiovisual esta fase es una de las más estimulantes al tratarse del momento en el que la ficción empieza a desvelar su apariencia, empieza a emerger del papel. En este caso sentimos este entusiasmo en los chicos que empezaron a crear, aún por grupos, la lista de atrezo y de vestuario que necesitábamos para recrear el guión. Una vez elaborada, se puso en común y se discriminaron todos aquellos elementos prescindibles. Por ejemplo: en lugar de comprar un bigote para el padre del niño, decidimos usar un lápiz de ojos y crear uno “dibujado”. Como nuestro presupuesto era nulo, propusimos a los chicos que identificaran todos los objetos que pudieran traer de sus casas. Y el resto, lo compramos nosotros en un supermercado de Istok $^{15}$.

Además, llegó la hora de escoger los actores que harían el papel de los personajes del guión. Todos los niños querían alguno de los papeles concretos y otros decidieron intervenir como parte de un grupo. Ninguno rehusó a aparecer en pantalla. Entre gran alboroto y diversión, llevamos a cabo los primeros ensayos y lectura pormenorizada del texto de cada personaje de manera individual. Pedimos como requisito imprescindible para el rodaje que todos los actores reflexionaran sobre su texto para el día siguiente. La idea era que aún no trayéndolo memorizado, sí fueran capaces de reproducir su significado principal durante la acción.

7. Rodaje. La última tarde del taller se dedicó enteramente al apartado principal. Este es el momento en el que todo lo pensado, sentido y hecho se transforma en materia. Imagen en movimiento.

Para el asombro de la profesora del centro que nos acompañaba, todos los actores aseguraron poder recitar su texto y diálogos sin problemas. Me resultó especialmente admirable el esfuerzo del actor que representaba al niño pobre, de unos 8 años.

Sin embargo, había un problema que se nos antojaba muy complicado a priori y que solucionamos gracias a la eficiencia de una de las participantes del taller. La barrera idiomática es protagonista en la fase que requiere mayor interacción entre el equipo técnico y artístico del taller. Veíamos muy difícil sincronizarnos con los participantes a

\footnotetext{
${ }^{15}$ Municipio de Kosovo donde residíamos y en el que se encontraba la base militar de las fuerzas armadas españolas desplegadas en la región (KFOR) hasta el desalojo de tropas en el año 2009, razón por la cual los cooperantes de la ONG nos alojamos allí.
} 
la hora de saber cuándo terminaba una toma, qué parte del guión se estaba trabajando, a partir de qué punto han de repetir un diálogo. Para ese fin, nombramos a una de las chicas más atentas y comprometidas para que cumpliera la función de script. La joven se encargaba, en todo momento, de anotar las incidencias de rodaje, controlar la coherencia cronológica de lo rodado, asegurarse de que no faltara ninguna frase de guión y comentarnos en qué punto se había fallado y desde que otro recomenzar. Toda esta información, traducida por nuestra intérprete, nos permitía interactuar en el curso del rodaje con mucha mayor fluidez.

El rodaje resultó muy intenso. Esfuerzo, concentración, colaboración de todos, silencios compartidos, risas y vuelta a empezar.

Antes de comenzar, elaboramos un Plan de Rodaje aproximado: cuánto tiempo dedicar a cada secuencia y en qué orden rodarlas (en función de la disponibilidad de las localizaciones, todas ellas ubicadas en el interior del colegio y en su patio exterior). También redactamos un sencillo Guión Técnico, cómo contar la historia de manera visual: tipo de planos, movimiento de cámara, posición de los actores, etc. Cada intérprete sugería el punto de vista y el tipo de plano para su escena. Y ésta era grupal, se decidía por consenso.

No faltaron ni los apuntadores espontáneos ni los nervios de la primera vez. Pero sobre todo cabe destacar la diversión, el disfrute y la sensación de creación que reflejaron los niños durante el proceso de filmación y durante la despedida del taller. Ésta tuvo lugar tras la fiesta representada al final del guión, que decidimos hacer de verdad preparando refrescos, aperitivos y música. Así, la realidad y la ficción se unieron al término del taller, encuentro en el que comentamos el trabajo realizado y las sensaciones de cada uno, bailamos y nos emocionamos.

Nota aclaratoria: El material grabado lo transportamos a España con la intención de editarlo. Hasta la fecha de hoy no se ha podido realizar el montaje por falta de infraestructura técnica para efectuar la captura de las imágenes al soporte informático. Seguimos esperando un oportunidad para hacerlo y enviárselo a los autores, para que la realidad vuelva a cruzarse con la ficción. 


\section{Bibliografía:}

De la Torre, Saturnino. (1996). Cine formativo. Una estrategia innovadora para los docentes. Barcelona: Octaedro.

De la Torre, Saturnino. (2005). El cine, un entorno educativo. Madrid: Narcea.

Ferrés, Joan. (1994). La publicidad, modelo para la enseñanza. Madrid: Akal.

Moles, Abraham. (1978). Sociodinámica de la Cultura. Barcelona: Paidós.

Tardy, Michel. (1978). El profesor y las imágenes. Barcelona: Planeta Paideia.

Tarkovski, Andrei. (1991). Esculpir en el tiempo. Madrid: Rialp.

Torres, Jurjo. (1998). Globalización e interdisciplinariedad: El currículum integrado. Madrid: Morata. 